Indian f. Psychiat. (1989), 31(3), 238-240

\title{
SCHIZOPHRENIA AND SEASON OF BIRTH
}

\author{
RAKESH KUMAR JANG!D', S. M. VERMA ${ }^{1}$
}

\section{SUMMARX}

A comparison with respect to the season of birth in 380 schizophrenic patients with 685 control subjects revealed an excess of winter births in the former by $6.1 \%$.

The stress literature in schizophrenia reflects the choice made by the researchers in the field. They have studied and rated events that tend to be externally caused and that are usually experienced as unpleasant and undesirable.

A $15 \%$ excess above the expectation was found in winter bitth in the Philipines, an equatorial region (Parker et al., 1977).

As compared with controls, the schizophrenics show an excess (about $8 \%$ ) of winter births and a smaller excess (about 4\%) of spring births. The excess of winter births in schizophrenics has been reported from Scandintvian countries (Odegard, 1974; Videbech et al., 1974), England and Wales (Hare, 1975), United States (Torrey et al., 1977, Pulver et al., 1981), Japan (Shimura, et al., 1977), and Australia (Parker et al., 1976). No strong evidence from a similar birth pattern was found in patients with manic depressive psychosis.

The notion of seasonal variation among Australian-born schizophrenics as compared with other psychiatric diagnoses was not supported. In fact statistically non-significant trend was towards the summer and the autumn, contrary to northern hemis. phere studies which were towards winter and spring. It was suggested that this failure to obtain seasonal variations in birth could be duc: to less marked climatic differences between the Australian seasons (Kru- pinshi et al., 1976).

Keeping in mind the above controversies the authors of the present study planned to find out the status of seasonality of birth in schizophrenics compared with normal control group in India.

\section{MATERIAL AND METHODS}

Patients attending the Out patient department at the Central Institute of Psychiatry, Ranchi whose dates of birth were definitely known and were provisionally diagnosed as schizophrenia were taken as an experimental group. Their diagnoses were further confirmed by the authors using ICD-9 criteria. Patients with a history of drug abuse, dependence, and concurrent medical illnesses (e.g. Hypertension, Diabetes etc.) and a diagnosis of schizoaffective illness were excluded.

The control group was obtained by interviewing the guardians of the patients attending the OPD at C.I.P. Ranchi whose dates of birth were definitely known. Individuals with a history of psychiatric illness were excluded.

The authors have obtained a homogeneous sample. In both the groups the subjects borne in the northern districts of Bihar (including West Champaran, East Champaran, Sitamadi, Mathubani, Saharasa, Purnia, Gopal Ganj, Muzaffarpur, Dharbhanga, Madhepura, Katihar, Sivan, Saran,

f. Senior Revidents, Central Inatitute of Psychiatry, Kanke, Ranchj-834006. 
Vaishali, Samastipur, Khagaria, Bhojpur, Patna, Rohtas, Jahanabad, Nalanda, Munger, Bhagalpur, Godadda, and Sahibganj) were selected. This geographical belt experiences a similar climatic condition. In this way the participants of our study had experienced a homogeneous climatic condition at the time of birth in the particular calendar month of the year.

\section{RESULTS}

In this study finally 380 schizophrenic patients and 685 control subjects fulfilled the required criteria. $74 \%$ of schizophrenics and $62 \%$ of control subjects belong to the younger age group, i.e. in the range of 20-34 years. Majority of them were male i.e. $74 \%$ and $76 \%$ for schizophrenics and control subjects respectively.

Broadly we can divide the seasons into three groups i.e. Winter (November to February), Summer (March to June), and Monsoon (July to October). We found a statistically non-significant excess of winter birth (by $6.1 \%$ ) in schizophrenics as compared to the control group as shown in Table $\left(\mathrm{X}^{2}=4.45\right.$, d.f. $=2$, N.S. $)$.

TaBuE. Distribution of subjects acterding to the season of birth

\begin{tabular}{lcc}
$\begin{array}{c}\text { Season } \\
\text { of birth }\end{array}$ & $\begin{array}{c}\text { Schizophrenics } \\
(\mathrm{N}=390)\end{array}$ & $\begin{array}{c}\text { Control } \\
(\mathrm{N}=685)\end{array}$ \\
\hline Winter & 158 & 243 \\
& $(41.6 \%)$ & $(35.5 \%)$ \\
Summer & 92 & 197 \\
& $(24.2 \%)$ & $(28.8 \%)$ \\
Monsoon & 130 & 245 \\
& $(34.2 \%)$ & $(35.7 \%)$ \\
\hline
\end{tabular}

$X^{2}=4.45$, d.f. $=2$, N.S.

\section{DISCUSSION}

The etiology of schizophrenia is a debatable topic. Most of the literature point towards an excess of winter birth in a geographical area where the climatic differences are more marked. Our study also supported a similar trend. We have found a statistically insignificant excess of winter births in schizophrenics as compared to control group by $6.1 \%$. As such this difference had reached to a level of statistical significance only in few studies.

It is suggested that studies taking general population as control group should be under. taken. It may also be worthwhile to study the difference in the incidence of schizophrenia in different geographical areas where winter predominates (e.g. Jammu and Kashmir, and Himachal Pradesh) and to compare it with other geographical belts.

\section{Acknowledgement}

The authors acknowledge the thanks to Mr. B. Mishra, M.Sc., MRT (Delhi,) ATMR (Mclbourne) for extending his help in data coljection.

\section{RFFERENCES}

Bailar, J. C. and Gurian, J. M. (1965). Congenital malformation and season of birth-a brief review. Eugen Quarterly, 12, 146-153.

Cancro, R. (1985). In: Comprehensive Text book of Psychiatry. IV edition, (Eds.), Kaplan, Harold I \& Sadock, Benjamin J., Baltimore/London: Williams \& Wilkins, 631-643.

Hare, H. (1975). Season of birth in Schizophrenia and Neuroses. American Journal of Psychiatry, 132(ii), 1168-1171.

Krupinshi, J.; Stoller, A. and King, D. (1976). Season of birth in Schizophrenia an Australian study. Australian and New Zealand Joumal of Psychiatry, $10,311-314$.

Odegard, $O$. (1974). Season of birth in the general population and in patients with mental divorder in Norwary. British Journal of Psychiatry, 125, 395. 405.

Parkar, G, and Nelson, M. (1976). Mental Disorder and season of birth-A Southern Hemsiphere study. British Journal of Psychiatry, I29, 355. 361 .

Parkar, G. and Balza, B. (1977). Season of birth and schizophrenia-an equitorial study. Acta Psychiatrica Scandinavia, 56(2), 149-146. 
Pulver, A. E.; Stewart, W. Carpenter, W. T. and Child. B. (1983). Risk factors in schizophrenia, season of hirth in Maryland, U.S.A. British Journal of Psychiatry, 143, 389-396.

Shimura, M.; Nakamura. I. and Miura, T. (1977). Season of births of schizophrenics in Tokyo, Japan. Acta Psuchiatrica Scandinavia, 55(3), 225-232.
Torrey, E. F., Torrey, B. B. and Peterson, M. R. (1977). Seasonality of schizophrenic births in the United States. Archives of General Psychiatry, 34, 1065. 1070.

Videbech, T.; Weeke, A. and Dupont, A. (1974). Endogenous psychoses and season of birth. Acta Psychiatrica Scandinavia, 50, 202-218. 